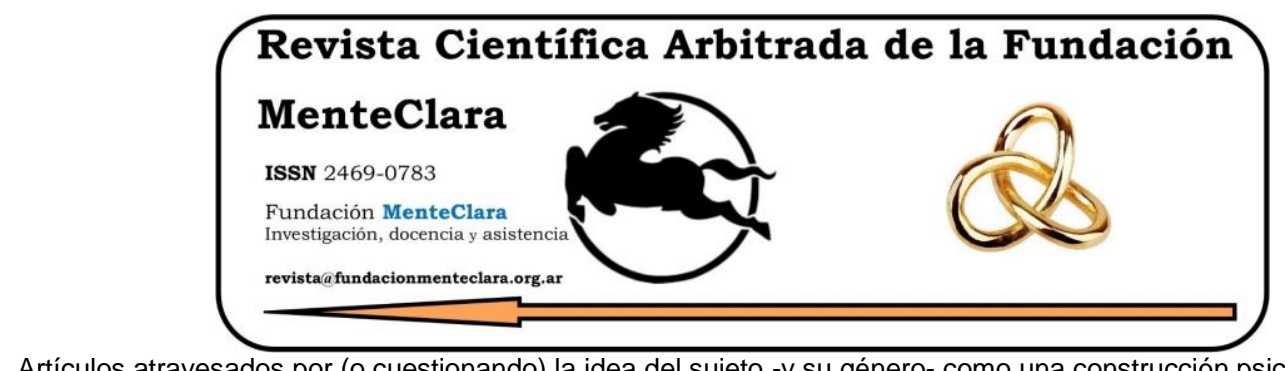

Artículos atravesados por (o cuestionando) la idea del sujeto -y su género- como una construcción psicobiológica de la cultura. Articles driven by (or questioning) the idea of the subject -and their gender- as a cultural psychobiological construction.

Vol. 5 (2020), enero-diciembre

ISSN 2469-0783

https://datahub.io/dataset/2020-5-e197

\title{
LOS TRES PROBLEMAS FILOSÓFICOS EN EL PENSAMIENTO PRIMITIVO
}

\author{
THE THREE PHILOSOPHICAL PROBLEMS IN PRIMITIVE THOUGHT
}

Antonio Ñahuincopa Arango antonio3560@gmail.com

Universidad de Navarra, España

Cómo citar este artículo / Citation: Nahuincopa Arango A. (2020). "Los tres problemas filosóficos en el pensamiento primitivo". Revista Científica Arbitrada de la Fundación MenteClara, Vol. 5 (197). DOI: https://doi.org/10.32351/rca.v5.197

Copyright: (C) 2020 RCAFMC. Este artículo de acceso abierto es distribuido bajo los términos de la licencia Creative Commons Attribution 4.0 International License (CC BY 4.0). Recibido: 24/11/2020. Aceptado: 02/12/2020 Publicación online: 03/12/2020

Conflicto de intereses: Ninguno que declarar.

Nota del Autor: Las palabras en quechua que aparecen en este articulo son simplemente ilustrativas; ya que, para el autor, son una alternativa a la discusión sobre el término "presocrático", que renombra como buscadores de la verdad, y el amor al idioma materno.

\section{Resumen}

En este artículo estudio y analizo de forma tripartita algunas cuestiones fundamentales en los presocráticos: en primer lugar, se aborda el problema de superación del mito por el logos; como segundo punto, el asunto del origen: ¿cuál es el principio de todas las cosas? Y, en tercer lugar, se examina la cuestión de lo uno y lo múltiple: ¿cómo puede derivarse lo distinto a partir de lo idéntico? - tema que es abordado desde la interpretación polémica de Platón y Aristóteles sobre el pensamiento de Parménides (ser inmóvil) y Heráclito (el devenir) y su posible solución. Estas tres cuestiones tienen su relevancia, pero de modo especial la pregunta por el origen. Dado que, es una pregunta clave que nos lleva también a interrogarnos sobre nosotros mismos, como seres inteligentes, capaces de otear, ver y analizar como de una montaña los problemas existenciales y trascendentales de la realidad. Para una mejor compresión, empiezo con las cuestiones preliminares. 


\begin{abstract}
Seeking In this article I study and analyze in a tripartite way some fundamental questions in the pre-Socratics: first, the problem of overcoming myth by logos is addressed; as a second point, the question of origin: what is the beginning of all things? And thirdly, the question of the one and the many is examined: how can the different be derived from the identical? - A topic that is approached from the controversial interpretation of Plato and Aristotle on the thought of Parmenides (being immobile) and Heraclitus (becoming) and its possible solution. These three questions are relevant, but especially the question of origin. Since, it is a key question that also leads us to question ourselves, as intelligent beings, capable of observing, seeing and analyzing the existential and transcendental problems of reality like a mountain. For a better understanding, I start with the preliminary questions.
\end{abstract}

Palabras Claves: mito; filosofia; Aristóteles; lo múltiple; presocráticos; chiqap maskaq Keywords: myth; philosophy; Aristotle; the multiple; pre-Socratic; chiqap maskaq 


\section{Introducción}

La filosofia se preocupa de estudiar la realidad en su totalidad y temas más radicales en la búsqueda de la verdad. Precisamente, en esta búsqueda de la verdad en el pensamiento de los presocráticos ${ }^{1}$, nos topamos con tres dificultades relevantes: el problema del arjé de la realidad, que propició el nacimiento de la filosofia occidental; la cuestión superación del mito por el logos; el uno y lo múltiple; No obstante, para estudiar el pensamiento de estos buscadores de la verdad de los tres primeros siglos -chiqap maskaq, kimsa pachak wata-, es preciso dejar a un lado nuestras mochilas, pues, a veces vamos cargados de prejuicios, soberbia o encasillados con una estructura mental: queremos entender la antigüedad con las nociones de tiempo, de ciencia, de física y cosmos que tenemos actualmente o fuera del contexto. Por otra parte, no contamos lamentablemente con escritos de primera mano sobre el pensamiento completo de ellos, sólo se conservan pequeños fragmentos recopilados y comentados por los filósofos posteriores a Aristóteles que llegan hasta Simplicio -VI d. C-. Recién a principios del siglo XX se realiza la primera recopilación sistemática de dichos fragmentos por los alemanes Hermann Diels y Walter Kranz² (Palazzo, 2015), que es una referencia para posteriores ediciones.

En este trabajo de investigación, se analiza el problema de la superación del mito por el logos. Es interesante saber qué entendian estos pensadores por el mito. Si éste es sinónimo de superstición para los griegos y si esta superación fue progresiva o de modo inmediato.

\footnotetext{
${ }^{1}$ El término presocrático, que es ya una tradición, es discutible porque no es preciso cronológica ni temáticamente: hay filósofos contemporáneos o incluso más jóvenes que Sócrates. Tampoco estos pensadores se han dedicado exclusivamente a la interpretación de physis, ni que con Sócrates empieza la antropología propiamente, sino también abordaron temas antropológicos y otros. Prefiero llamarlos, en este trabajo los pensadores primitivos o de los tres primeros siglos o los chiqap maskaq kimsa pachak wata (en quechua).

${ }^{2}$ Esta obra, en suma, está dividida en secciones numeradas, que corresponde a cada pensador. Y cada sección subdivida en dos: 1) representada con la letra A para los testimonios; 2) y la letra B para los fragmentos.
} 
Asimismo, sabiendo que cada filósofo es hijo de su tiempo, estos investigadores no parten de cero, sino que recogen aportes importantes de la tradición mitológica-politeísta y a la vez, anuncian y preparan el terreno al clasicismo griego de la filosofia antigua.

En segundo lugar, se estudia la cuestión: ¿cuál es el origen de todas las cosas? Este interrogante es troncal y encuentra distintas respuestas en este elenco de pensadores primitivos, que van desde un elemento material como el agua, el aire y el fuego hasta los números y el ser.

El problema de lo uno y lo múltiple es una cuestión colosal: ya es clásico la oposición que hay entre el pensamiento de Heráclito y Parménides, como se imparte en algunas cátedras universitarias. Empero, ¿estos autores interpretaron correctamente o se sirvieron de ellos polemizándolos para construir su propio sistema filosófico como sostiene Harold Cherniss? (Esquivel, 2000) ¿Cómo sería el conocimiento que tenemos de estos pensadores sin el intermediario de Platón y Aristóteles?

Nuestro trabajo, sin perder el rigor científico, no pretende ser prolijo, sino sencillo. El propósito es desglosar desde el abanico de posibilidades de los temas en estos investigadores arcaicos, tres cuestiones fundamentales y radicales. Dedicamos un apartado al contexto histórico, porque pensamos que sin éste no se podrian comprender, analizar y valorar los problemas cruciales y el pensamiento de los chiqap maskaq.

Finalmente, el pensamiento de los indagadores primitivos sigue siendo vigente en la actualidad $\mathrm{y}$ ha despertado interés en la filosofia contemporánea, por citar alguno: Hegel, Nietzsche, Heidegger y Gadamer. Conocer la historia de la filosofia, mejor dicho, el origen de ésta desde su raíz, a pesar de las dificultades en las fuentes, nos da un bagaje cultural sólido y de rigor científico. 


\section{Cuestiones preliminares}

Para no perder el horizonte es conveniente destacar el contexto histórico donde se mueven estos investigadores ${ }^{3}$. En la explicación del asunto, acudo analógicamente a términos futbolísticos: se necesita "la cancha" o el estadio, el balón y los jugadores para jugar un partido. El estadio, en este caso, es el ambiente o los antecedentes históricos. Los jugadores son los pensadores primitivos de los tres primeros siglos. Y el balón es el problema al que se enfrentan. Nos ubicamos concretamente en "el estadio" del pueblo: pensamiento, idioma y escritura griega. Y nos enfrentamos a tres problemas fundamentales en el pensamiento presocrático.

Los principales lugares del quehacer filosófico son las colonias griegas de Asia Menor: Mileto, actual costa occidental de Turquía; Éfeso, Elea y Sur de Italia (Hegel, 1995). ¿Por qué nace la filosofia precisamente en estos pueblitos y no en Grecia central como Atenas? Entre otras cosas, en estas zonas, el comercio marítimo - trató de unir Grecia con el resto del mundo de aquel tiempo- el cual, facilitó un próspero crecimiento económico. Éste, a su vez, favoreció el ocio o recreación, una ocasión propicia para filosofar (Esquivel, 2000). El quehacer filosófico de los pensadores primitivos se desarrolló a lo largo de los siglos VI y V e incluso desde finales del siglo anterior (Schneider, 2005).

Por otra parte, hay un saber común, pero no existe un concepto de ciencia y menos como se concibe actualmente desde Newton. Tampoco se puede distinguir bien entre la ciencia y filosofia. Hay una especie de argamasa entre el mito, ciencias experimentales y la filosofia. Hay que esperar a Platón y Aristóteles. Este último acuñó por primera vez, como estudio cierto de algo, lo conocido por sus causas, clasificadas en

\footnotetext{
${ }^{3}$ Uso este término, porque realmente tratan de investigar algo nuevo, desconocido para el mundo de aquel tiempo. Además, estos hombres son astrónomos, matemáticos, médicos, músicos, etc. Alcmeón, por ejemplo, siendo médico, hace filosofía.
} 
teóricas, prácticas y productivas. Dicho de otro modo "toda ciencia investiga ciertos principios y causas concernientes a todas las cosas" (Metafísica. 1063b 35). En el mundo griego de aquellos tiempos, su religión es principalmente politeísta. Sus dioses son antropomorfizados, que toman figuras humanas: sentimientos, emociones e incluso celos. Explican, a su modo, el origen del mundo, la existencia y la de los dioses -teogonía-. Los cuales son expresados en sus poemas, por ejemplo, la Iliada y Odisea de Homero; Trabajos y dias y Teogonía de Hesíodo4. "El vehículo normal del mito es la poesía" (Bernabé, 2008). El mundo surge de algo material pre existente por algún dios, aunque sea caótico (Cañas, 2012). No hay, por tanto, una creación ex nihilo, esto es, de la nada como en el cristianismo.

¿Qué es lo que hacía esta gente? Como dice con razón Néstor L. Cordero (2016): “intentaban encontrar una explicación global de la realidad, de todo, del todo, para poder proponer normas de vida en función de las respuestas que encontraban", aunque centran su interés en el estudio de la physis o naturaleza. A pesar de ello, no descuidan temas éticos, teología, antropologia, teoría del conocimiento y metafísicos como Pitágoras, Jenófanes de Colofón, Alcmeón de Crotona, Heráclito y Parménides.

¿Qué factores proporcionaron al nacimiento de esta nueva perspectiva filosófica de la realidad? Entre ellos, podemos destacar en el campo económico: la prosperidad. La filosofia nace en un momento de crecimiento económico en toda Grecia, que pasó, poco a poco, de una sociedad eminentemente agrícola y ganadera a desarrollar un gran flujo mercantil y comercial (Schneider, 2005). Una parte de la población, especialmente de estas pequeñas colonias, como ya hemos mencionado,

\footnotetext{
${ }^{4}$ También es interesante las poesías de Cleobulo, Safo, Píndaro y Teognis. Cfr. Romero, A. J. C. (2018). El origen de la filosofía a través de la investigación y del pensamiento mítico, en el período presocrático.
} 
tiene suficiente tiempo libre, porque no están preocupados por ganarse el pan del día. Estos investigadores no pasan necesidad económica y disponen de mucho tiempo de ocio, por tanto, puede dedicarse a la reflexión. ¡Insisto en general, ninguno es pobre! También es relevante la crematística, o sea, la invención de la moneda. Esta trajo una transformación social, pues, ya no es necesario el trueque, y así hombre rico es quien posee mayor cantidad de dinero, no sólo de tierras. Otro aspecto no de menor importancia, en el campo religioso, es la ausencia de verdades reveladas, dogmas y libro canónico (Esquivel, 2000). Esto les da a tener una mentalidad abierta sin que se produzca roces con la fe politeísta de la griega pagana. Por eso, no hay ninguna contradicción entre la fe, ciencia y filosofia.

¿Cómo llega hasta nosotros el pensamiento de estos filósofos? Hemos dicho, que en general, conservamos solamente fragmentos o trozo de textos, pues, quizá alguno de ellos no ha escrito nada ${ }^{5}$-si han escrito algo- la mayoría se han perdido. Los fragmentos -citas literales, explicaciones o paráfrasis- sobre el pensamiento de estos filósofos van desde Platón hasta Simplicio (Olmos, 2016). Platón y Aristóteles comentan y facilitan vislumbrar el pensamiento y la existencia de ellos, siendo principales fuentes. Y los demás son prácticamente referencias u opiniones de los comentaristas platónico y aristotélico ${ }^{6}$. Hasta qué punto son fiables éstos, es otra cuestión.

\footnotetext{
${ }^{5}$ Según Hegel, no poseemos ninguna obra de Tales, ni se sabe siquiera si llegó a componer alguna. Aunque, "Diógenes Laercio (I, 23, 34-35) habla de doscientos versos sobre temas de astronomía y de algunos pensamientos suyos expresados en forma de sentencias, por el estilo de ésta; La abundancia de palabras no prueba la justeza de las opiniones." (p. 160)

${ }^{6}$ Fuente secundaria: Plutarco, Clemente de Alejandría y Hipólito. La tradición doxográfica integrada por Diógenes Laercio y Aecio. Esta, a la vez, se inspiró en la obra de duodécimo director de Liceo Teofrasto opiniones de los físicos -que también se ha perdido.
} 


\section{El problema de la superación del mito}

Empezamos nuestro cometido con una pregunta: ¿En qué sentido tratan de superar el mito, los filósofos primitivos? Antes de responder la cuestión, es preciso señalar, qué entendían los griegos por el mito. ¿Acaso el mito griego es como lo entendemos ahora nosotros? ¡Por supuesto que no! El mito ${ }^{7}$ no tiene una faceta negativa, sinónimo de superstición, como sostuvo Hegel, sino una forma positiva de saber sobre la realidad y es parte integrante de la vida en todas las facetas del pueblo griego ${ }^{8}$. Por eso, éstos no parten de cero en su estudio o investigación filosóficas sino, al contrario, se apoyan precisamente en los philómythos -amante del mito- de sus predecesores y contemporáneos; puesto que "los elementos míticos y racionales están muy relacionados" (Jaeger, 1992).

En este punto, conviene matizar las cosas para no pecar por defecto ni por exceso, ya que ambas posturas son extremas. Para ello nos serviremos del método analógico, esto es, ver las semejanzas y las diferencias que hay entre ellos. Ambos tienen algo en común al hombre. Éste hace la valoración tanto mítica como la filosófica de la physis: ambos se preocupan sobre el origen del universo, de los dioses, de los propios seres humanos. Por otra parte, son dos vías que tratan de explicar una única realidad a su modo, es decir, coinciden en el objeto material. Aunque, hay diferencias destacables en ellos en la forma de abordar la cuestión (Bernabé, 2008). La valoración mítica es algo concreto o parcial, que ve solo una parte de la realidad, pues narra un conjunto de sucesos determinados que sucedieron en un territorio y momentos concretos, $\mathrm{y}$ cuyos personajes son limitados, por ejemplo, Aquiles, el héroe de la Guerra de Troya. La especulación filosófica es universal porque indaga a

\footnotetext{
${ }^{7}$ Es un tipo de relato, narración de un acontecimiento asombroso; incluso es anterior a la escritura. Es una forma de sabiduría o especie de "religiosidad popular". Y fue encarnado en edificios y estatuas del pueblo griego.

${ }^{8}$ En toda regla hay una excepción, es el caso de Jenófanes de Colofón quién criticó principalmente el antropomorfismo de la mitología de Homero y Hesíodo, manifestado en sus acciones injustas: robar, cometer adulterio y engañarse unos a otros.
} 
base de conceptos y abstracciones, y estudia las cosas en su totalidad. En segundo lugar, el mito exige un elenco de creencias y propone causas ocultas indemostrables: Por medio de la diosa Gea surge el universo, la primera raza de los dioses, los Titanes, y los primeros humanos; el trueno y los terremotos obedecen a fuerzas sobrenaturales. La filosofia, en cambio, busca precisamente y trata de demostrar la causa de la realidad. En tercer lugar, el mito es una explicación narrativa e imaginativa de las cosas. A veces, ofrece dilucidaciones poco coherentes. Mas el pensamiento filosófico trata de buscar la explicación racional, el porqué de las cosas.

A pesar de todo, estos chiqap maskaq, no fueron conformistas, sino que trataron de hacer algo original para su tiempo. Miran la misma realidad, pero con ojos distintos. En pocas palabras, con una nueva perspectiva distinta a los anteriores. Utilizando el lenguaje de la construcción, podemos afirmar, que con los alcances que habían logrado los amantes de la mitología en la explicación del mundo, empiezan a cimentar un edificio nuevo que hasta entonces no estaba construido. Con los ladrillos obtenidos por los predecesores -que ellos todavía no han construido valga la redundancia- empiezan a hacer algo dificil y colosal, un palacio filosófico, quizá no será para el gusto de algunas personas, pero interesante. Por cierto, esta obra no está concluida, a pesar que han pasado muchos siglos, ni se completará, porque el día que se termine de construir, se habrá finiquitado la filosofia. En este campo, las posibles soluciones de un pensador se convierten en el punto de partida para otros; por consiguiente, una conclusión es, a la vez, una brecha de problemas o cuestionamientos. Por eso, es digno de aprender la postura de estos hombres fundadores de la filosofia. No son fundamentalistas ni dogmatistas, sino tienen una mentalidad abierta. Haciendo una comparación con la agricultura, podemos decir: son buenos chacareros, 
saben escoger el grano de la paja. Asimismo, como sabemos, no hay nada original de todo, no hay nada totalmente nuevo, nadie parte de cero o de la nada en sus pensamientos. Así pues, Platón y Aristóteles cómo hubieran empezado su especulación filosófica sin conocer la reflexión de los chiqap maskaq. Creo que no hubiesen existido los cinco capitulos del primer libro de la metafísica, por decir algo. Quizá el destino hubiera sido distinto. Pero la principal diferencia entre éstos y aquéllos radica en la pregunta formal que hace Tales de Mileto -que al parecer supone el Estagirita- por el origen de las cosas y su propuesta. A partir de aquí empieza los cuestionamientos, discusiones intelectuales que tratan de buscar distintas soluciones a la cuestión. De esta manera, introduce Aristóteles a Tales en el campo o estadio de la filosofia. Y éste empieza a desarrollar una teoría filosófica, aun de modo incipiente e imperfecta, buscando una explicación racional, preguntando el porqué de las cosas. En suma, estos pensadores "crearon una nueva actitud racional ante la explicación del mundo" (Bernabé, 2008), en consecuencia, iniciaron el pensamiento racional.

Finalmente, puedo afirmar que el paso del mito al logos fue progresivo, no de golpe y definitivo; dicho de otra manera, no es posible que estos pensadores dejaran a un lado sus creencias, y se entregaran a la explicación de la naturaleza y, que el entendimiento haya progresado debido al "milagro griego" (López, 2020) como sostuvieron Burnet y Snel19. Aquel sostiene dos cuestiones: por un lado, que los pensadores jonios "han franqueado la vía que la ciencia, a partir de este momento, no ha tenido más que seguir" (Vernant, 1973). Y por otro, parece que el logos haya enterrado de sopetón al mito como lo manifiesta expresamente

\footnotetext{
${ }^{9}$ Aunque John Burnet expresan la opinión común de principios del siglo XX y tiene eco en Bruno Snell que, en los pensadores jonios, el logos se libera, de golpe, de las concepciones míticas imperantes. Actualmente es un asunto abierto. Conviene investigar la cuestión a fondo para acercarnos a la verdad, ya que existen también opiniones contrarias como de Cornford, Cappelletti, Bernabé y otros.
} 
Burnet (1994): "sería enteramente falso buscar los origenes de la ciencia jónica en una concepción mitica cualquiera". Según la interpretación de Snell, "el logos se habría liberado del mito de igual modo que las escamas se desprenden de los ojos del ciego. Más que de un cambio de actitud intelectual, de una mutación mental, se trataria de una revelación decisiva y definitiva: el descubrimiento de la razón" como refiere Vernant (Ibidem). En cambio, prueba de ello podemos sostener, que los jonios, aunque "no hablaron de los dioses como agentes directos y personales de los sucesos, si partieron de un trasfondo 'divino' que subyace en la naturaleza y que la hace posible" (Cañas, 2012). Aún existen algunos vestigios o elementos míticos, por ejemplo, en el ápeiron de Anaximandro (López, 2020); en el poema de Parménides -una diosa guía al estudiante en el conocimiento de la verdad- aunque el contenido es una especulación metafísica. Heráclito juega a los dados con los niños en el templo de artemisa. En pleno apogeo de la filosofia clásica griega, Aristocles, apodado Platón, acude a este recurso en las explicaciones metafísicas o antropológicas, como es el mito de la caverna. Asimismo, para Aristóteles hay una cierta sabiduría en el mito, y al abordar el origen de la filosofia encuentra un origen común con éste, porque ambos nacen de la admiración o asombro: "el que se siente perplejo y maravillado reconoce que no sabe-de ahí que el amante del mito sea, a su modo, 'amante de la sabiduria': y es que el mito se compone de maravillas-" (Metafisica. 982b 15-20). En último lugar, el papiro de Derveni 10 (Bernabé, 2004), muestra la estrecha relación que hay entre los presocráticos y elementos órficos e incluso en Platón ${ }^{11}$.

\footnotetext{
${ }^{10}$ De autor anónimo es un texto de carácter religioso y teogónico atribuido a Orfeo, del siglo IV a.C.

${ }^{11}$ Esta idea es subyacente, en el tema "Parménides y el orfismo" presentado por Alberto Bernabé, el 10 de octubre de 2003 , en una reunión de la Sociedad Ibérica de Filosofía Griega.
} 
Por consiguiente, podemos sostener, que tanto el mito como la especulación filosófica son dos vertientes para explicar una sola realidad. Coexistieron siglos, nunca estuvieron opuestos. Más bien interrelacionados, puesto que son complementarios. Además, como sostiene Héctor Esquivel (2000), "dificilmente se puede concebir la filosofia como un pensamiento puro, es decir, sin relación con el mito".

\section{El problema del principio: arjé de las cosas}

Este tema es el "problema de los problemas". Es "la madre del cordero" de las otras cuestiones filosóficas; puesto que, con la pregunta por el origen, se introducen también una serie de cuestiones en el pensamiento de los tres primeros siglos. Los primitivos pensadores, suscitados o movidos por la admiración de fenómenos naturales de la realidad ${ }^{12}$ que tuvieron al frente -como dice Aristóteles por las particularidades de la luna, sol, las galaxias, etc.-, se plantean una cuestión fundamental, entre otros puntos, ¿cuál es el origen de todo? Dicho de otro modo, ¿de qué están hechas las múltiples cosas que habitan la physis? Se preguntan por el principio, aunque ellos no acuñaron este término ${ }^{13}$, le dieron un contenido filosófico. Justamente con esta pregunta se inicia formal y propiamente el quehacer filosófico, y, Tales de Mileto se consagra como el primer filósofo. El arjé es el punto clave y la llave que abre el tesoro de la caja fuerte de la realidad. Apoyándonos en la expresión de la minería, podemos señalar: que la filosofia es la veta para explorar racionalmente "esas rocas gigantes" del cosmos, la vida, la inmortalidad, Dios, etc. En cambio, conviene hacer aquí una aclaración: para la mentalidad griega

\footnotetext{
${ }^{12}$ No es de origen griego, sino proviene de una palabra latina res, que significa "cosa". Nosotros usamos indistintamente los dos términos.

${ }^{13}$ Esta palabra ya aparece en Hesíodo: “Oh Musas que poseéis palacios olímpicos, contadme desde el principio, y decidme cuál de ellos nació el primero. Ciertamente, el primero de todos nació Caos, después Gea de ancho seno..." (Teogonía 114120). Asimismo, no es fácil de definir porque tiene diversos matices para los griegos.
} 
no hay un concepto de creación en el tiempo y además ex nihilo, hay que esperar el cristianismo. La noción del tiempo no es lineal como para nosotros, sino es cíclico -no hay inicio ni fin, es un eterno retorno, como veremos más adelante. La materia es eterna. La physis-traducida al latín por naturaleza, nacer- comprende tanto los seres materiales como no materiales. El cosmos significa precisamente el orden (Calvo, 2000). El logos es el encargado de reunir y unificar lo distinto en un todo en el cosmos que tiene una ley, al menos a partir de Heráclito. El arjé de las cosas hay que buscarlo en la misma physis. Cuando se habla de lo "divino" no se refiere generalmente a alguna fuerza sobrenatural, ni mucho menos al Dios cristiano, sino que la misma materia tiene cierta vitalidad en sí misma, esto es, principio vital. Por eso, el agua, el aire y el fuego tendrán connotaciones divinas como el mismo logos.

Retomando el tema, los chiqap maskaq se interesan por el del fundamento, lo que tienen en común y lo que se repite al descomponer sus elementos. Para ellos, el arjé no solo es el origen de donde proceden todas las cosas, sino también el "lugar" a donde vuelven al ser aniquiladas o al descomponerse. Además, el arjé es el todo, fuera de él no existe nada. Por decirlo de una manera simple, en el arjé está metido desde el microbio, un elefante e incluso los dioses, al menos, en los investigadores arcaicos jonios.

Con respecto a la cantidad y a la especie del arjé, no hay unanimidad. Empecemos por los que han propuesto un solo elemento, llamados por la tradición los monistas. Según el Estagirita, como refiere en su Metafísica, Tales de Mileto (ca 640-546 a. C.) es el primero que marca el hito e introdujo otra forma de pensar. El principio de todas las cosas es el agua.

Tales, el introductor de este tipo de filosofia, dice que es el agua -de ahí que dijera también que la tierra está sobre el agua-, tomando esta idea posiblemente de que veía que el alimento de todos los seres es 
húmedo y que a partir de ello se genera lo caliente mismo y de ello vive pues aquello a partir de lo cual se generan todas las cosas es el principio de todas ellas- tomando, pues, tal idea de esto, y también de que las semillas de todas las cosas son de naturaleza húmeda, y que el agua es, a su vez, el principio de la naturaleza de las cosas húmedas (Met. 983b 19-26).

Es una respuesta natural y racional. No obstante, su importancia radica, no en la respuesta que da este autor, que es algo simple, pues incluso Homero ya había dicho que el cosmos proviene del Océano, sino más bien, por la forma de plantear y explicar el problema. Esto es, no se limita a observar los hechos fenoménicos y contentarse con una interpretación o respuesta mitológica. Al contrario, empieza a justificar su respuesta con argumento o explicación racional: el alimento y las semillas son de naturaleza húmeda; todas las cosas que hay en la naturaleza se componen del agua e incluso la tierra está sobre el agua. Cuando todo se seca ya se mueren. Pues, sin agua, no hay vida. No se refiere como un elemento químico que tiene composición $\mathrm{H}_{2} \mathrm{O}$, sino como algo divino o principio vital. Sin embargo, ¿cómo es posible que una cosa material, como el agua, que se diferencia del aire, el fuego y la tierra puede unificar las cosas y estos elementos tampoco la tengan? A partir de ahora, los que quieran vestirse con la camiseta y pertenecer al equipo de los filósofos, tendrán que aprender a argumentar sus posiciones o propuestas, explicando el porqué de las cosas. Por eso, en este camino de especulación filosófica, el problema se agravará aún más.

El segundo investigador es Anaximandro de Mileto (610-547 a.C.) quién propone precisamente algo distinto del anterior: el ápeiron. Es lo indefinido e indeterminado o lo intermedio entre dos elementos. Tampoco es un elemento sensible. 
Como los que dicen que el todo es una naturaleza única, por ejemplo, agua o fuego o lo intermedio (Física. 189b). El principio y elemento de las cosas existentes era el ápeiron, habiendo sido el primero en introducir este nombre. (10114 Simplicio. Fís 24, 13).

Arguye que el ápeiron engendra las cosas a través de un proceso de separación de sustancias opuestas. En esta separación se producen innumerables universos, que se dan en una especie eterno retorno o ciclo eterno. Por ejemplo: la tierra surgió de lo indeterminado, por medio de un desarrollo de separación de elementos contrarios. Del elemento primigenio se separan originalmente lo gélido y lo cálido; gracias al fuego de estos dos fenómenos sale lo seco y lo húmedo. Finalmente, por el calor el agua se evapora dando origen a la tierra seca y el cielo se forma a partir de la nube de vapor. Todo surge y todo regresa al ápeiron según el eterno retorno. Sus principales atributos son inengendrado, indestructible y eterno. También hay una dificultad: ¿Cómo es posible que una cosa indeterminada pueda ser la identidad de cosas determinadas?

Para Anaximenes (ca. 588-524 a.C.) el principio de todas las cosas es el aire. "Anaxímenes y Diógenes piensan que el aire es anterior al agua, y primer principio entre los cuerpos simples" (Met. 984a 5). Aduce que del aire brotan todas las cosas por condensación y rarefacción y es anterior al agua. De forma gradual, por condensación se origina primero el viento, luego las nubes, el agua, la tierra y las piedras. Por rarefacción -dilatación- se origina el fuego (140 Simplicio Fís. 24, 26). Además, el aire y el movimiento están muy relacionados. Todas las cosas se transforman gracias al movimiento y el aire está en constante movimiento. En realidad, esta propuesta es parecida a la de Tales, pero con diferente matiz como manifiesta Hegel (1995), "el aire tiene, al mismo tiempo, la ventaja de poseer una mayor ausencia de forma: tiene menos de cuerpo

\footnotetext{
${ }^{14}$ Para mayor compresión, seguimos la numeración propuesta tanto por los autores Kirk- Raven como de Eggers Lan - Juliá.
} 
que el agua, pues no lo vemos, sino que nos damos cuenta solamente de sus movimientos". Estos jonios, como hemos visto, -a excepción de Anaximandro- ofrecen en sus propuestas principios materiales, apostando por un solo elemento. De la misma forma, harán los pluralistas, aunque con propuestas de varios elementos, pero en el fondo son materiales.

Dejemos atrás a estos monistas, para subir un peldaño más en la escalera de las propuestas. Según Pitágoras (ca. 570-497) y pitagóricos, "la sustancia, la esencia de las cosas hay que buscarla en el número; el número no es algo sensible, ni tampoco el pensamiento puro, sino el principio de todas las cosas" (Hegel, 1995). La realidad está de alguna manera matematizada: antes que existan - el agua, el aire, fuego y el ápeiron- está el par y lo impar. "Supusieron que los elementos de los números son elementos de todas las cosas que son, y que el firmamento entero es armonía y número" (Met. 986 a). Estos elementos son principalmente lo Par-limitado y lo Impar-ilimitado que componen la unidad. La unidad es el principio de los números, mejor dicho, el Número deriva del Uno. Puede presentarse como principal argumento: los intervalos musicales que hay en las notas de la lira pueden expresarse numéricamente. Los sonidos y la armonía musical pueden ser reducidos a números. ¿Y la armonía del universo? Las cosas no solo son numerables, sino números. Además, todas las oposiciones se reducen a oposiciones entre números: pares e impares. El límite hace posible la medida -la perfección o lo bueno-, y lo ilimitado la excluye (Manzano, 2011). Con todo ello, los pitagóricos se ubican en el segundo grado de abstracción correspondiente a las matemáticas. Es un paso más con respecto a los jonios. No obstante, los números siendo abstractos, ¿cómo pueden ser principios que articulen la semejanza con la desemejanza? 
Tanto Heráclito como Parménides merecen otro tratamiento, puesto que están en otro ámbito de especulación. Aquí solo dedicamos unas pinceladas. El fuego ${ }^{15}$ es la causa y origen de todo, en Heráclito (ca.536470). "Hipaso de Metaponto y Heráclito de Éfeso dicen que el elemento es uno, en movimiento y limitado, pero hacen del fuego el principio" (593. 22 A5 Simpl., Fís. 23,33). Colige que el fuego fluye por todas cosas como el oro por los mercados; del fuego surge toda la realidad y acaba al extinguirse éste. El fuego, al condensarse, se humedece; y comprimido se convierte en agua; y el agua, al congelarse se hace sólido y vuelva convertirse en fuego. Atraviesa todas las cosas, las consume y las transforma, pues, está en continuo flujo (Palazzo, 2015). Además, este fuego es eterno y divino. Para Heráclito, como refiere Clemente de Alejandria: "Este cosmos no lo hizo nadie ni dios ni ningún hombre, sino que siempre fue, es y será fuego, que se enciende según medida y se extingue según medida" (217 Fr. 30, Clemente, Strom. V 104). En resumen, todo surge del fuego y todo vuelve a él, según el eterno retorno. Empero, no es un volver otra vez a lo que habian iniciado sus paisanos, los jonios Tales y Anaxímenes. Aunque la explicación cosmogónica sea parecida a ellos, esto sólo es el inicio del pensamiento de este investigador oscuro y enigmático. El fuego divino y eterno no se entiende sin acudir al logos, tampoco sin la armonía de los opuestos y el devenir. En el fondo, el fuego es el logos en la physis. Por ello, hay un orden y no el caos en el mundo. En efecto, existe una armonía en los opuestos o contrarios, porque hay una ley en la naturaleza. En cambio, la teoria de los contarios, ya está en los filósofos anteriores, por consiguiente, no es "un descubrimiento de Heráclito" (García, 1984). Para Parménides ${ }^{16}$ de Elea

\footnotetext{
${ }^{15}$ Sobre qué es el fuego heraclíteo rebasa el límite este artículo. Menciono algunas interpretaciones de especialistas: es sólo una substancia material, como el agua de Tales (Burnet); substancia material y símbolo (Zeller); atributo del pensamiento (Gigon y Reinhardt.

${ }^{16}$ Parménides es propiamente el precursor de la metafísica con su gran descubrimiento del ser. ¿Qué es el ser? Aún todavía no tiene respuesta satisfactoria.
} 
(ca.515 a.C) lo primero que existe ante cualquier cosa es el ser, es decir, que hay ser. En efecto, “como considera que, aparte de 'lo que es', no hay en absoluto 'lo que no es', piensa que hay solamente una cosa, lo que es y nada más" (Met. 986b 10). "Es una misma cosa el Pensar con el ser" (García-Bacca, 1979). Para este autor, sólo el ser se puede conocer y el no-ser es incognoscible. Con el descubrimiento del "ser", se introduce propiamente en el campo de la filosofia, otro nivel de abstracción.

Hasta aquí, parecía que se había superado los elementos materiales; sin embargo, vuelven a aparecer de nuevo las propuestas fisicas, aunque con algunos matices, es decir, con pluralidad de elementos. Al fin y al cabo, son materiales. Son los que han recibido el nombre de pluralistas y son los últimos presocráticos. Esta forma de quehacer filosófico de los chiqap maskaq es una muestra del modo cómo progresa la filosofia. ¿Qué quiere decir esto? La filosofia no avanza de modo lineal, como las ciencias experimentales, sino es accidentado como las montañas de los Andes peruanos con sus bajadas y subidas. Dicho de otro modo, no todo filósofo posterior tiene que superar necesariamente en el pensamiento, al anterior; sino en cuanto más se acerca a la verdad.

El agua, aire, fuego y la tierra que se unen y se separan respectivamente por el amor y el odio en Empédocles de Agrigento (ca. 483-430 a.C.). "Escucha primero las cuatro raíces de todas las cosas: Zeus resplandeciente, Hera dadora de vida, Edoneo y Nestis, que con sus lágrimas empapan las fuentes de los mortales"17 (Fr. 6, Aecio 3,20).

Además, fue afirmar en que son cuatro los elementos que se dicen tales en el sentido de "materia" -Ciertamente, no se sirve de ellos como efectivamente cuatro, sino como si fuera solamente dos: el fuego por sí mismo de una parte, y de otra parte, la tierra, el aire y el agua, opuestos

\footnotetext{
${ }^{17}$ Nestis es el agua. Zeus es el fuego; Hera, el aire y Edoneo, la tierra, según Teofrasto.
} 
a aquél y como una única naturaleza. Esto puede captarse considerando su Poema- (Met., I 985 a 31-985b 2).

Empédocles declara, que de la mezcla y separación de estos elementos surgen todas las cosas. El universo se disgrega de los elementos bajo la acción del Odio y por medio de la Amistad, se forma la unidad del universo. Este indagador se distingue de los anteriores, pues, introduce dos principios del movimiento -el Odio y la Amistad- que son a la vez, distintos y contrarios. Estas dos fuerzas cósmicas trascienden a la materia. Y cada uno de los elementos es eterno, pero su mezcla da lugar a la multiplicidad perecedera.

Para Anaxágoras de Clazomene (ca. 499-428 a. C) el arjé de toda la realidad son las homeomerias.

Que los principios son infinitos: en suma, viene a decir que todos los cuerpos homeoméricos, como el agua o el fuego, se generan y destruyen únicamente por reunión y separación, pero que en ningún otro sentido se generan o destruyen, sino que, antes bien, permanecen eternos (Met., 984 a12-16).

Arguye que todas cosas surgen de las famosas homeomerias. Es decir, de la mezcla de múltiples elementos que son como unas semillas de las cosas. Estos elementos son infinitos en número, infinitamente divisibles y cualitativamente distintos. Pero quien mezcla, ordena y separa estas semillas es la Nous, una inteligencia ordenadora. "Después de que la Nous comenzó a mover, se fue separando de todo lo movido, y todo cuanto movió la Nous se separó" (DK 59, B13). Hay un avance en este pensador con respecto a los anteriores, pues, estas semillas en sí mismas no pueden ser la causa de las cosas, sino que necesitan de alguna manera de otro, que sería el artífice de los cambios, de las mezclas y separación 
-la Nous- una causa eficiente. Sin embargo, ¿cómo se articulan esta inteligencia con las homeomerias?

Para Demócrito de Abdera (ca. 460- 370) y Leucipo (fl. 440 a.C) ${ }^{18}$ el origen de toda la realidad está en los átomos.

Son elementos el lleno y el vacío, denominando al uno "lo que es" y al otro, "lo que no es": al lleno y sólido, "lo que es" y al vacío, "lo que no es" ... éstos son las causas de las cosas que son, entendiendo "causa" como materia (Met. 985b 5-9).

Argumentan: la realidad se compone de átomos, que son infinitos, físicamente indivisible, sólidos, homogéneos indestructibles, dotados de movimiento propio y cualitativamente idénticos y se distinguen por su forma y su posición. La existencia del espacio vacío es la condición para el movimiento de los mismos. Su funcionamiento es puramente mecánico. Estos autores identificaron el átomo con el ser y el no-ser con el vacío. El vacío es lo contario de aquello. Esta manera de pensar será refutada por Meliso, un filósofo de Samos. Según éste, el no -ser no existe, tampoco el vacío. Y que el ser ocupa todo el espacio.

Estos chiqap maskaq empiezan realmente un trabajo filosófico, aunque de modo incipiente. Buscan una teoria que explique sus dudas. Hay un cierto progreso paulatino en cuanto a la forma de filosofar, como también en las propuestas presentadas sobre la cuestión del origen: elementos materiales, los números y la noción del ser.

\section{El problema de lo uno y lo múltiple}

$\mathrm{El}$ arjé, que es lo idéntico en la desemejanza y viceversa, que busca la causa sobre de qué está hecho el mundo, engendra otras dificultades en

\footnotetext{
${ }^{18}$ Ya son contemporáneos de Sócrates y de los sofistas.
} 
los albores del pensamiento filosófico: por un lado, si el principio es uno o muchos; los opuestos también son principios. Hay autores partidarios de un solo principio como Tales, Anaximenes y Heráclito, que proponen una materia primordial única que daría origen a la multiplicidad. Para Empédocles, Anaxágoras y los atomistas sostienen, en el origen de todas las cosas, más de un elemento primordial. Por otro, ¿cómo articular la unidad con la multiplicidad? Puesto que el "arjé es el motor que pone marcha el proceso de lo uno a lo múltiple” (Bernabé, 1997).

En la multiplicidad de cambios, hay cosas que permanecen -los primitivos pensadores son conscientes de ello- un niño nace, se hace joven; luego, adulto o anciano. Empero, hay algo que no cambia en él: su humanidad. Aunque no es lo mismo un niño de cinco años que un joven de veinte, a pesar que conserva su esencia. Este descubrimiento de lo permanente, les permitió clasificar, por ejemplo, los seres del universo en varios grupos: minerales, vegetales, animales y hombres. Asimismo, tienen una experiencia de lo que es generación y corrupción, uno nace y muere; la leña se convierte en ceniza. ¿Cómo se explican estos cambios en la multiplicidad? ¿Hay algo que permanece a pesar de esas transformaciones? En general, aunque su interés está centrado en el problema de los problemas, el principio. Estas cuestiones están latentes y hay algunos barruntos en estos investigadores, pues, no se puede abordar la cuestión del origen sin hacer relación a este asunto, que es la otra cara del problema. En todo caso, no tienen suficientes herramientas para explicarlos.

Sin embargo, a raíz de la interpretación sobre el pensamiento de Heráclito “todo cambia” y Parménides "ser inmóvil" -que hace Platón, luego, Aristóteles, que ya es una tradición- se polemiza la cuestión. Según Néstor Cordero (2016), Platón en el Sofista, trata de presentar un epítome de los filósofos anteriores y los agrupó en dos bandos: por un 
lado, los defensores del mundo sensible, los herederos de Heráclito, para quienes todo es relativo. Por otro, los defensores del ser inmutable, herederos de Parménides, que niegan el cambio. Asimismo, el Estagirita presenta sus innovaciones como una superación del pasado, y Parménides sostenía que el "ser" tenía un solo sentido. Con todo, siendo contemporáneos estos investigadores, si realmente se conocieron y discutieron sus posturas a pesar de vivir en los extremos de la colonia griega: Éfeso y Elea, es otra cuestión que sobrepasa el cometido este artículo.

Ahora bien, presentemos algunos testimonios de Platón basados fundamentalmente en Crátilo y Teeteto:

En algún lugar dice Heráclito que todo se mueve y nada permanece, y, comparando las cosas con la corriente de un río, dice que en el mismo río no nos bañamos dos veces (Crát. 401d); que todo fluye como cántaros (Crát. 402a). Jamás nada es, siempre deviene: en esto coinciden todos los sabios -excepto Parménides-, en serie, Protágoras, Heráclito, Empédocles (Teet.152e). Según Homero, Heráclito y toda esta tribu, todas las cosas se mueven como corrientes (Teet.160d).

La manifestación del filósofo de Estagira sobre el pensador enigmático:

Platón... de joven se hizo primero discípulo de Crátilo y adhirió a las doctrinas heracliteas de que todas las cosas sensibles fluyen siempre y no hay ciencia de ellas (Met. 987 a). Y además los primeros que hablaron de la naturaleza. Éstos dicen que todas las demás cosas se generan y fluyen, sin que haya nada firme, pero que sólo una cosa permanece, de la cual todas aquéllas nacen por transformación: esto parecen querer decir Heráclito de Éfeso y muchos otros (Sobre el cielo 289b 29).

Según estos testimonios de los dos grandes de la filosofia clásica griega, se colige que Heráclito es el filósofo del devenir, del cambio. Que 
nada permanece al menos en el mundo sensible. Si hay devenir, hay pluralidad de cambios. Si nada permanece, ¿podremos conocer realmente las cosas? Son interrogantes que podemos plantearnos. Como dice Carlos Olmos (2016) quizá es relevante hacer una nueva interpretación de la filosofia heraclitea a través de otros diálogos platónicos, superando el panta rei de Crátilo.

Ahora expongamos el pensamiento de Parménides, que para Platón era terrible y le pareció una locura a Aristóteles:

Pues jamás se impondrá esto: que haya cosas que no sean (Sof. 258 d). Pero por poco me olvido... "inmóvil es el nombre para todo el ser" y cuantas otras cosas Meliso y Parménides afirmen con fuerza oponiéndose a todos ellos, asegurando que todo es uno y permanece estable idéntico a sí mismo, en sí mismo, careciendo de lugar en el cual se pudiera mover (Teet. 180 e). Y así, extremando las consecuencias inmediatas, llegaron a afirmar que no existe la multiplicidad, sino sólo el Ser mismo (Fís.191a 33-34).

Lo mismo pasa con este pensador que con Heráclito. El filósofo de Elea, según los textos aducidos, parece sostener el ser inmóvil, que nada cambia y que todo es permanente. Si el ser es uno e inmóvil para Parménides ¿cómo es que existen muchos seres y el movimiento?

Pese a todo, centrándonos en la cuestión disputatis podemos plantearnos que, según la interpretación de Platón y Aristóteles, cómo se puede concertar las dos posturas extremas. Heráclito que defiende el devenir ${ }^{19}$ o cambio en detrimento de la identidad; mientras Parménides destaca el ser inmóvil negando todo cambio. Platón presenta aparentemente una posición conciliadora, como solución al asunto,

\footnotetext{
${ }^{19} \mathrm{Si}$ esto fuera así, como interpretar estos dos textos del mismo pensador: "Tras haber oído al Logos y no a mí es sabio convenir en que todas las cosas son una" (196 Fr.50). "Las cosas en conjunto son todo y no todo, idéntico, armónico y no armónico, lo uno nace del todo y del todo nacen todas las cosas" (203 Fr.10) Por qué habla de la unidad si todo cambia.
} 
dividiendo la realidad en dos niveles: el mundo de las ideas y el mundo sensible. Según la teoría de la Ideas, las Formas son permanentes y pertenecerian al mundo empíreo o de las ideas. Por todo ello, la postura de Parménides encajaría en el mundo de las ideas identificándose con las formas. Mientras tanto, la posición de Heráclito con el mundo sensible, manteniéndose los cambios o el devenir. Sin embargo, esta solución no es acertada. Porque al duplicar el cosmos en dos: sólo el mundo super Urano tiene existencia real y el mundo sensible es aparente. Es una copia del mundo empíreo. Platón extrae el problema del contexto. El cual tiene que solucionarse dentro del plano donde se ha planteado, no fuera.

Por otra parte, no sabemos la intención de Aristóteles en la valoración del pensamiento de estos chiqap maskaq. Si es una crítica constructiva o destructiva para construir su propio sistema filosófico, considerando sus pensamientos como erróneos y sepultándolos intelectualmente (Cherniss, 1991). Mas, no podemos dejar de resaltar la importancia de su aporte. Es el descubrimiento de ciertas nociones metafisicas y que son claves para entender la filosofia occidental hasta el dia de hoy. El conocimiento de potencia -acto (Met. 1019 a 15- 1019b5) ayudan a explicar el cambio o movimiento metafísico (Fís. 200b- 201b10); los conceptos de sustancia- accidentes (Met.1025a 15- 30) exponen la identidad y la multiplicidad; la materia y forma o hilemorfismo (Met. 1043a 30- 1043b 20) indagan los cambios profundos o sustanciales. Finalmente, el sentido del ser, sirve para soslayar que éste tiene varios significados y no es unívoco. Este genio griego con estos hallazgos trata de dar solución al problema de lo uno y lo múltiple, esto es, a la polémica del devenir y el ser inmóvil. Este asunto intenta explicar de la siguiente manera: el sustrato que permanece en los múltiples cambios es la sustancia. Esta es definida como aquella realidad cuya naturaleza le compete ser en sí, no en otro sujeto. Distinto son los accidentes que 
tienen el ser en otro sujeto. Los que padecen los cambios o alteraciones son precisamente los accidentes. Según el Estagirita, el cambio o movimiento ${ }^{20}$ es el paso de la potencia al acto. Mientras tanto, la sustancia permanece en estos cambios múltiples que se dan en los seres contingentes. Aunque, existen también cambios sustanciales. Sin embargo, en los cambios sustanciales permanece la materia prima que pierde y adquiere una nueva forma sustancial. Por consiguiente, según Aristóteles, existe el movimiento y la multiplicidad, porque hay seres en potencia o en acto. Y también hay algo que no cambia, mejor dicho, permanece en el cambio, en contra del pensamiento de Heráclito. Del mismo modo, hay varias maneras de predicar el ser. Así, el ser es sustancia, accidente, potencia, acto o veritativo (Met.1026b-1027a 25). Por ende, el sentido del ser es análogo y no univoco, como aparentemente sostenía Parménides.

\section{Conclusión}

A los que nos dedicamos a la filosofia nos es relevante el descubrimiento de la verdad -venga de donde venga o diga quién lo digapara ser cada día mejores personas y en la medida de lo posible alcanzar nuestra felicidad, aunque sea relativa. El trabajo filosófico supone una larga reflexión y diálogo con la realidad. Donde se descubren realmente problemas radicales para el ser humano, como lo hicieron estos pensadores primitivos. Una buena filosofia nos enseña precisamente a tener una mentalidad abierta y a dialogar con el pensamiento de cualquier autor -a pesar de los años o siglos de distancia- corrigiendo los errores y valorando sus aciertos por medio de una actitud crítica

\footnotetext{
${ }^{20}$ Con esta noción se refiere por antonomasia al movimiento metafísico que el físico. Para entender bien es necesario conocer los conceptos de potencia y acto.
} 
meliorativa $^{21}$. Los llamados chiqap maskaq -con sus limitaciones y desaciertos- realizaron interesantes aportes y desafios a la filosofia posterior. Prueba de ello, Aristóteles dedica cinco capítulos en el primer libro de la Metafísica y siete, en el libro de Física.

Estos investigadores primitivos se apoyaron en la especulación mítica de sus predecesores. Abordan la misma realidad, pero con una nueva perspectiva y originalidad, que es la especulación racional totalmente nueva. Aquélla es algo valiosa, es una forma primitiva de saber sobre la realidad con el ingenio e imaginación humano como lo hicieron, por ejemplo, los poetas o philómythos. La superación del mito fue progresiva y lenta. Asimismo, tanto la sabiduría mítica como la filosófica son dos caras de la misma moneda, pues, cada una trata de interpretar la misma realidad por distintos métodos y perspectivas. Se puede decir que la filosofia en su origen, nace de lo que el mito se compone -de maravillas y de acontecimientos asombrosos- sin quedarse en el asombro.

La pregunta por el origen es una cuestión fundamental, no un simple interrogante sino un cuestionamiento que buscaba el "pez gordo" de la realidad interpelada. Esta cuestión es clave para el surgimiento del pensamiento especulativo, supuso la "superación" del mito, engendró el problema de lo uno y lo múltiple y abrió un nuevo camino de cómo debe ser el trabajo filosófico occidental. Es una pregunta modelo o de referencia que nos enseña a buscar y ver la realidad desde una perspectiva nueva. A partir de aquí, los pensadores -que quieran vestirse con la camiseta de la filosofia o tener el perfil de filósofos- tienen que preocuparse de los problemas más radicales de la realidad: el hombre, el mundo, Dios, inmortalidad del alma (Ñahuincopa, 2017), la felicidad, relación mente-cerebro, de la pandemia del COVID-19. Esta forma de pensar les hace distinguir de otros investigadores -científicos, médicos,

\footnotetext{
${ }^{21}$ No es una crítica a ultranza (extrema o criticismo) como lo han hecho Descartes o Kant.
} 
cosmólogos, biólogos y virólogos, por ejemplo- que también estudian la misma realidad. Pero, desde otras perspectivas.

El problema de lo uno y lo múltiple es la otra cara de la moneda engendrada por el problema del principio. Los filósofos primitivos, no tienen suficientes herramientas para afrontarlos. Tanto Platón como Aristóteles interpretaron de una forma dialéctica el pensamiento de Heráclito - panta rei, todo cambia- y Parménides -nada cambia-. ¿Esto es realmente el pensamiento de los filósofos de Éfeso y de Elea? Quizá conviene hacer una interpretación nueva al margen de los comentarios de Platón y Aristóteles armando los rompecabezas de los fragmentos para acércanos al pensamiento genuino de estos autores. Finalmente, el pensamiento de los investigadores primitivos está mediatizado por el de Platón y principalmente del Estagirita, como pasó con los pensadores del Renacimiento barroco: Suárez, Báñez y Toledo dependen mucho del Aquinate en la comprensión del pensamiento de Aristóteles. 


\section{Referencias}

Aristóteles (1995). Physica. Física, Introducción, traducción y notas de Guillermo R. de Echandia, Editorial Gredos, Madrid.

Aristóteles (1996). De coelo. Acerca del Cielo y Meteorológicos, Introducción, traducción y notas de Miguel Candel, Editorial Gredos, Madrid.

Aristóteles (1998). Metaphysica. Metafisica de Aristóteles, Edición trilingüe por Valentín Garcia Yebra, Editorial Gredos, Madrid.

Bernabé, A. (1997). "Lo uno y lo múltiple en la especulación presocrática: nociones, modelos y relaciones", Taula, quaderns de pensament, $\mathrm{N}^{\circ} 27-28$, Universitat de les Illes Balears, 75-100

Bernabé, A. (2004). Textos órficos y filosofia presocrática: materiales para una comparación, en Trotta, Madrid.

Bernabé, A (2008). Fragmentos presocráticos de Tales a Demócrito, Editorial Alianza, Madrid.

Burnet, J. (1994). La aurora de la filosofia griega, Traducido por Muñoz, Editorial Argos, México.

Calvo Martinez, T. (2000). "La noción de Physis en los orígenes de la filosofía griega" Daimon, Revista Internacional de Filosofia, $N^{\circ} 21$, Murcia, 21-38.

Cañas Quirós, R. (2012). "La Imagen teológica Del Cosmos En Los Albores De La filosofia: La Escuela De Mileto (Tales, Anaximandro Y Anaximenes)" Revista Espiga, Vol. 10, N 23, Escuela de Ciencias Sociales y Humanidades (ECSH), 1-23. Recuperado en: https://doi.org/10.22458/re.v10i23.997

Cherniss, H. (1991). La crítica aristotélica a la filosofia presocrática, Universidad Nacional Autónoma de México.

Cordero, N. L. (2016). "Heráclito y Parménides dos caras de la misma moneda" Revista filosófica Symploké, Buenos Aires, 4-11.

Diels, H. y Kranz, W. (1981). Filósofos presocráticos, Traducido por W. AA., Gredos, Madrid.

Eggers Lan, C. y Juliá, V.E. (1978). Los filósofos presocráticos, Vol. I, Gredos, Madrid.

Esquivel Estrada, N.H. (2000). "Consideraciones filosófico-científicas de tres filósofos presocráticos” CIENCIA ergo-sum, Vol. 7, $\mathrm{N}^{\circ} 3$, Universidad Autónoma de Estado de 
México, 300-307. Recuperado de:

https://cienciaergosum.uaemex.mx/article/view/7251

García Bacca, J. D. (1979). Los presocráticos, México, DF.

García Junceda, J. A. (1984). "Uno y múltiple: La dialéctica de los contrarios en Heráclito" en Anales Del Seminario De Historia De La Filosofia, 4, 29, Madrid, 29-44.

Hegel. (1995). Lecciones sobre la historia de la filosofia I. México: Editorial Fondo de Cultura Económica.

Jaeger, W. (1992). La teología de los primeros filósofos griegos, Fondo de Cultura Económica, México.

KirK, G.; Raven, J. y Schofield, M. (1994). Los filósofos presocráticos. Historia crítica con selección de textos, Editorial Gredos, Madrid.

López, M. A. (2020). "Entre mitología, filosofia y ciencia: lo apeiron y la imagen de Anaximandro transmitida por la doxografia" Theoría, Revista Del Colegio De Filosofia, N 37, México. Recuperado de: https://doi.org/10.22201/ffyl.16656415p.2019.37.1242

Manzano, J. (2011). Presocráticos a Sócrates, en Apuntes de Filosofia. Antigua. ITESO. Recuperado de: http://hdl.handle.net/11117/1302

Ñahuincopa Arango, A. (2017). ¿'Sostuvo Aristóteles la inmortalidad del alma? La respuesta de Suárez, Scientia et Fides 5 (1) 267-290.

Olmos, C. (2016). "Revisitando las fuentes y conceptos fundamentales de la filosofia de Heráclito de Éfeso" Mutatis Mutandis, Revista Internacional de Filosofia, Universidad Santiago de Chile, 25-43.

Palazzo S. (2015). Heráclito y Parménides. El Uno y lo múltiple, Editorial Salvat.

Platón (1992). Diálogos. Gorgias, Menéxeno, Eutidemo, Menón, Crátilo, Editorial Gredos, Madrid.

Platón (1992). Diálogos. Parménides, Teeteto, Sofista, Politico, Editorial Gredos, Madrid.

Schneider, J. S. (2005). "El nacimiento de la ciencia en los presocráticos" Serie Documentos de Trabajo, $N^{\circ} 304$, UCEMA, Buenos Aires.

Vernant, J. P. (1973). Mito y pensamiento en la Grecia antigua, Cap. VII, Traducido por Juan Diego López, Editorial Ariel, Barcelona. 